Available online on 15.11.2020 at http://jddtonline.info
Open Access to Pharmaceutical and Medical Research
unrestricted non-commercial use, provided the original work is properly cited

Open $\odot$ Access

Research Article

\title{
Assessment of Potentially Inappropriate Medications and Prescription Appropriateness in Geriatics at Teritiary Care Hospital
} \author{
Ateeq ${ }^{2}$ \\ ${ }^{1}$ PharmD PB Department of Pharmacy Practice, Mesco College of Pharmacy, Hyderabad, Telangana, India \\ ${ }^{2}$ HOD, Department of Pharmacy Practice, Mesco College of Pharmacy, Hyderabad, Telangana, India
}

Wazir Wahiba Mohammed 1*, Afreen Saba 1, Iffath Faria 1, Rafia Amtul Muqeet1, Ur Rahman Mohammed

\begin{abstract}
Background: Elder people are a diversified group commonly presenting with multiple comorbid illnesses resulting into multiple prescriptio ns which in turn increases adverse effects and polypharmacy. Potentially inappropriate medications (PIM) further contribute to this risk. Therefore, the aim of this study was to assess the prescription appropriateness and (PIM) in geriatrics as per WHO core prescribing indicators and Beer's Criteria, 2015 respectively.

Methods: A prospective observational study was conducted in Osmania General Hospital, a Tertiary Care Teaching Hospital from December 2018 to May 2019. A total of 100 case records of inpatients greater than or equal to 60 years of age, in general medicine wards were reviewed. Relevant information was recorded in a structured proforma and data was evaluated.

Results: Out of 100 patients, 70 patients were male and 30 patients were female. Majority of them were from the age group of $65-70$ years. There were $34 \%$ patients prescribed at least one PIM. Polypharmacy was observed in all patients. Average no. of drugs per prescription was 10.5\%.Percentage of drugs prescribed from EDL (Essential drug list) were 84\%.The p value of WHO core prescribing indicators was assessed using chi square test and was found to be significant.

Conclusion: Our study found WHO core prescribing indicators to be deviated from the optimum values set by WHO and high prevalence of Potentially Inappropriate Medications as per Beers criteria 2015. This highlights the need of future research work, strategies and regulatory measures focusing on geriatric patients and also encouraging prescribers to use the WHO core prescribing indicators and Beers criteria while prescribing elderly for providing optimum healthcare.
\end{abstract}

Keywords: Beer's criteria, Geriatrics, WHO prescribing indicators, Polypharmacy. Ageing, Potentially Inappropriate Medications.

Article Info: Received 24 Aug 2020; $\quad$ Review Completed 18 Oct 2020; $\quad$ Accepted 27 Oct 2020; $\quad$ Available online 15 Nov 2020

Cite this article as:

Wazir WM, Afreen S, Iffath F, Rafia AM, Ur Rahman MA, Assessment of Potentially Inappropriate Medications and Prescription Appropriateness in Geriatics at Teritiary Care Hospital, Journal of Drug Delivery and Therapeutics. 2020; 10(6):42-48 http://dx.doi.org/10.22270/jddt.v10i6.4542

*Address for Correspondence:

Wahiba Mohammed Wazir, MESCO College of Pharmacy, Hyderabad, Telangana (500006), India

\section{INTRODUCTION}

Ageing can be described as a progressive functional decline or a gradual deterioration of physiological function with age. 1 The national policy on older persons adopted by government of India in 1999 defines senior citizen or elderly as a person who is 60 years or above. ${ }^{2}$ The royal college of physicians (London) describes geriatric medicine as that branch of general medicine concerned with the clinical, preventive, remedial and social aspects of illness in older people". 3
The elderly are prone to various problems like musculoskeletal stiffness, poor nutrition, sexual dysfunction etc. The presentations of diseases are also particular to older population. These presentations of diseases have been described as the "giants of geriatrics". 4 The modern geriatric giants in elderly people are: "Instability, incontinence, intellectual impairment, incoherence (delirium), insulin resistance, immobility, inanition (malnutrition), and improvishment". India has around 100 million elderly populations and is expected to further increase to 323 million, constituting $20 \%$ of total population by $2050 .^{5}$ 
Polypharmacy, defined by the World Health Organization as "the administration of many drugs at the same time or the administration of an excessive number of drugs" is more common among the elderly as they mostly suffer from chronic diseases with concomitant pathologies. Inappropriate drug combinations, unnecessary medications, and inappropriate drugs for specific patients constitute the problems of polypharmacy. ${ }^{9}$

As older adults population is growing, the prevalence of chronic comorbid health conditions secondary to the inevitable nature of ageing expected to increase. This, therefore, is potentially associated with an increase in the use of multiple drugs (polypharmacy) to well manage these comorbidities or to prevent associated complications. ${ }^{6}$

Polypharmacy among older adults is common and consequently older patients are at higher risk of potentially inappropriate medications (PIMs) use. ${ }^{7}$ PIMs are defined as "medications that should be avoided due to their risk which outweighs their benefit and when there are equally or more effective but lower risk alternatives are available". 8 PIMs are considered one of the commonly encountered medicationrelated problems among the older population. The use of PIMs is commonly evaluated using different scales and criteria such as the Beers criteria, which are a set of explicit criteria to identify PIMs. It was first developed in 1991 and consequently updated with the latest update in $2015^{10}$. It is well known that PIMs use among older patients is associated with negative health consequences and can impact patients' quality of life. PIMs use increases the risk of hospitalization, drug-related problems and other adverse health outcomes by two to three folds 11,12 .

Rational drug use is defined as "Patients receive medications appropriate to their clinical needs, in doses that meet their own individual requirements, for an adequate period of time, and at the lowest cost to them and their community." (WHO, 1985). To improve rational drug use, the patient should receive medicines appropriate to the clinical indication, at optimum doses and sufficient time, as well as at the cost-effective and economical that the individual and the community can afford. The main aim of rational drug use is to encourage better quality of pharmaceutical care, to minimize the cost of drug therapy, to avoid preventable adverse drug reactions and drug interactions, to maximize therapeutic outcomes and to promote patient adherence. ${ }^{9}$

Till date there is a paucity of research work combining drug utilization pattern and potentially inappropriate prescribing in a special population such as elderly.

Objective: The aim of this study was to investigate the prevalence of potentially inappropriate medications prescribed for elderly patients in a tertiary care hospital, using recent updated Beers criteria 2015. In addition, this study has been investigated for the prescription appropriateness using WHO core prescribing indicators.

\section{MATERIALS AND METHODS}

The study was a prospective observational study conducted in 100 patients who were admitted in Department of General Medicine, Osmania General Hospital, Hyderabad, India. The duration of the study was six months.

\section{Inclusion Criteria:}

- $\quad$ Patients of either sex.

- Patients above 60 years of age.

- $\quad$ Patients willing to give their consent.

\section{Exclusion Criteria:}

- Patients who are admitted in departments other than General Medicine Department.

- Patients who are critically ill and receiving palliative care.

Relevant data was collected after obtaining patients consent on the approved Informed consent form from the patients.

The following data was collected on designed data collection form for the study by observing patients' case sheet and interviewing patient or patient representatives are Patient's demographic data, Prescription prescribed by the physician, Patients medications, medical and social history.

The data was assessed for prescription appropriateness using WHO core prescribing indicators and assessed the use of Potentially Inappropriate Medication (PIM) using Beer's criteria, 2015.

\section{Statistical Analysis:}

Data analysis was done based on the parameters assessed. The data was represented and the results were made by Graphical data representation using MS-Excel. Data was analyzed using Minitab version 19. The chi square goodness of-fit-test was used to compare the observed values and standard values of WHO core indicator.

\section{RESULTS}

\section{Gender Distribution:}

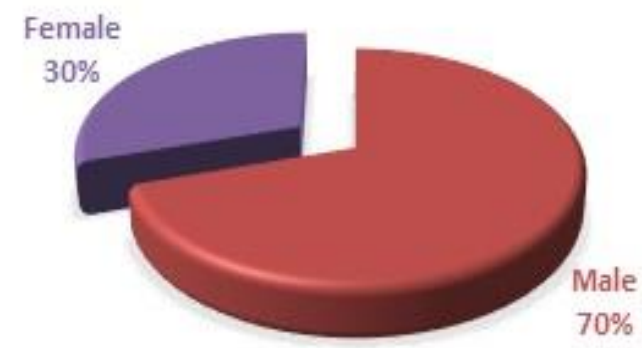

Graph 1: Distribution of geriatrics based on gender

Result: The study populations were 100 of whom 70 patients were Male which accounts for $70 \%$ and 30 patients were Females which accounts for $30 \%$.

\section{Distribution of Geriatrics Based on Age - Group:}

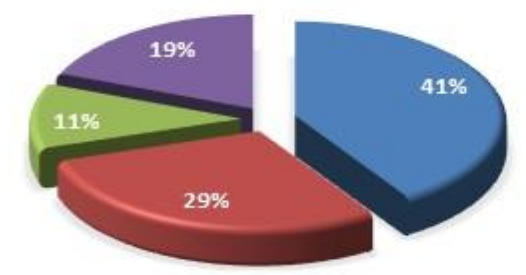

60-65

a $66-70$

a $71-75$

a $>75$

Graph 2: Distribution of geriatrics based on age group 
Result: Graph 2 shows that the Age Groups of geriatrics that are hospitalized are more common from 60-65 Years of Age (41 patients) followed by 66-70 years of age (29 patients).

\section{Distribution of Geriatrics Based on Localities:}

Table1: Distribution of geriatric based on localities.

\begin{tabular}{|c|c|}
\hline Locals & Non locals \\
\hline 45 & 55 \\
\hline
\end{tabular}

\section{Distribution of Disease:}

Table 2: Distribution of geriatrics based on disease

\begin{tabular}{|l|l|}
\multicolumn{1}{c}{ DISEASE } & NO. OF PATIENTS \\
\hline Hypertension & 36 \\
\hline CNS disorders & 32 \\
\hline Cardiovascular diseases & 30 \\
\hline Renal disorders & 24 \\
\hline Infectious diseases & 21 \\
\hline Respiratory diseases & 18 \\
\hline Diabetes & 15 \\
\hline Hypertension+Diabetes mellitus & 12 \\
\hline Others & 05 \\
\hline
\end{tabular}

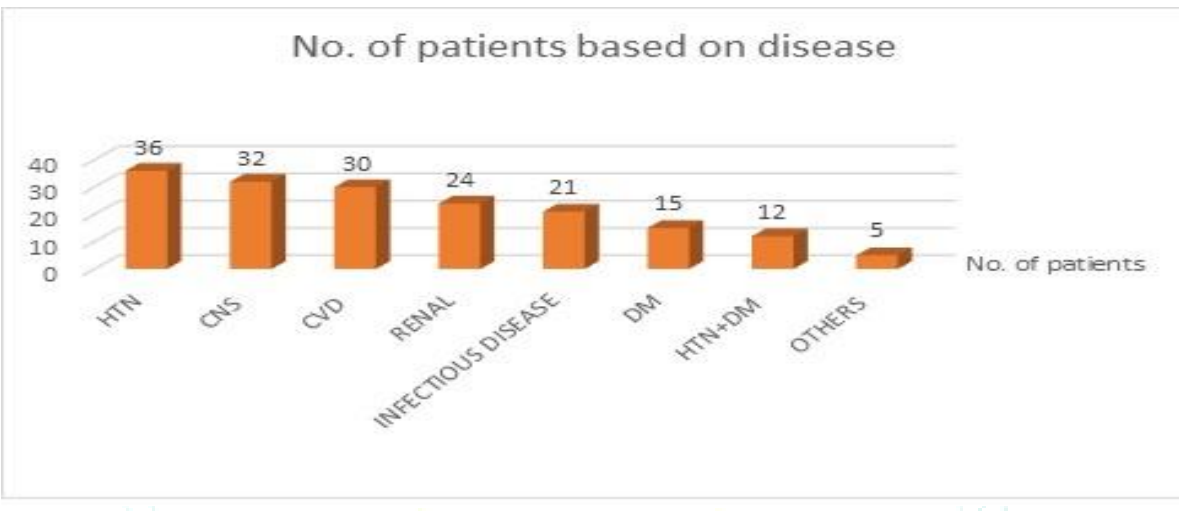

Graph 3: Distribution of geriatrics based on disease

\section{Class of Drugs:}

Table 3: Distribution of drugs based on category

\begin{tabular}{|l|l|}
\hline \multicolumn{1}{|c|}{ CATEGORY OF DRUGS } & NO.OF DRUGS \\
\hline $\begin{array}{l}\text { DRUGS ACTING ON CVS } \\
\text { (Atorvastatin, Amlodipine, Enalapril, Digoxin) }\end{array}$ & 173 \\
\hline $\begin{array}{l}\text { DRUGS ACTING ON GIT } \\
\text { (Pantoprazole, Ondansetron, Ranitidine) }\end{array}$ & 04 \\
\hline $\begin{array}{l}\text { DRUGS ACTING ON HAEMATOLOGICAL SYSTEM } \\
\text { (Iron Folic Acid) }\end{array}$ & 33 \\
\hline $\begin{array}{l}\text { ANALGESICS AND ANTI-INFLAMMATORY DRUGS } \\
\text { (Diclofenac, Aspirin, Acetaminophen) }\end{array}$ & 28 \\
\hline $\begin{array}{l}\text { RESPIRATORY SYSTEM DRUGS } \\
\text { (Deriphylline, Salbutamol, Hydrocortisone) }\end{array}$ & 13 \\
\hline $\begin{array}{l}\text { ENDOCRINAL SYSTEM DRUGS } \\
\text { (Insulin, Metformin) }\end{array}$ & 15 \\
\hline $\begin{array}{l}\text { CNS DRUGS } \\
\text { (Mannitol, Phenytoin, Lorazepam) }\end{array}$ & 104 \\
\hline $\begin{array}{l}\text { ANTI MICROBIALS } \\
\text { (Metronidazole, Ceftriaxone, Piperacillin) }\end{array}$ & 91 \\
\hline $\begin{array}{l}\text { VITAMINS AND MINERALS } \\
\text { (IV Fluids, Optineurin, B Complex) }\end{array}$ & 20 \\
\hline $\begin{array}{l}\text { ANTI HISTAMINE DRUGS } \\
\text { (Chlorpheniramine) }\end{array}$ & 04 \\
\hline
\end{tabular}

Result: The most commonly prescribed drugs were those acting on CVS, followed by Anti-microbial and Vitamin supplements.

\section{Who Core Indicators:}

Table 4: Assessment of data using WHO Core Prescribing Indicators

\begin{tabular}{|c|c|c|}
\hline CORE PRESCRIBING INDICATORS & OBSERVED VALUES & STANDARD VALUES \\
\hline AVERAGE NUMBER OF DRUGS PER PRESCRIPTION & 10.85 & $1.6-1.8$ \\
\hline PERCENTAGE OF DRUGS PRESCRIBED IN GENERIC NAME & $11 \%$ & $100 \%$ \\
\hline PERCENTAGE OF ENCOUNTERS WITH INJECTION PRESCRIBED & $57 \%$ & $13.4-24 \%$ \\
\hline PERCENTAGE OF ECOUNTERS WITH ANTIBIOTICS PRESCRIBED & $13 \%$ & $20-26 \%$ \\
\hline PERCENTAGE OF DRUGS PRESCRIBED FROM ESSENTIAL DRUG LIST & $84 \%$ & $100 \%$ \\
\hline
\end{tabular}




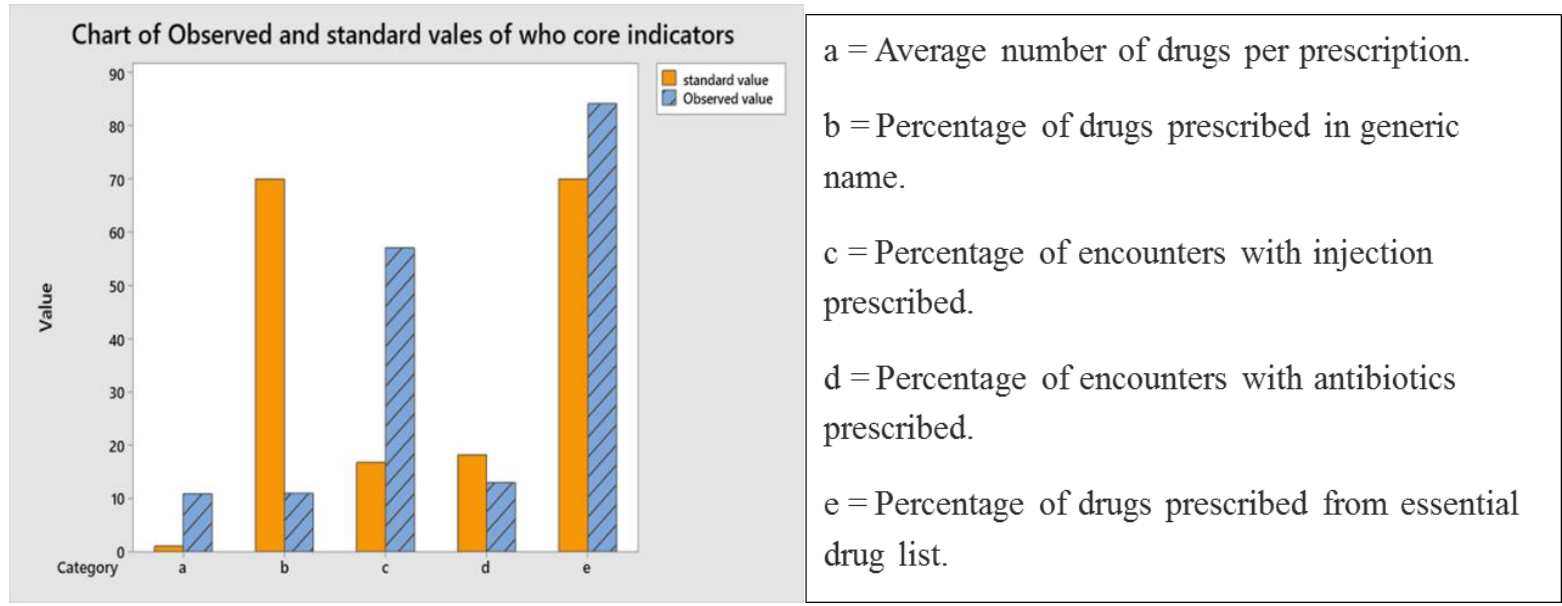

\section{Chi-Square Test:}

\begin{tabular}{|c|c|c|c|}
\hline N & DF & Chi-Sq & P-Value \\
\hline 175.85 & 4 & 235.097 & 0.000 \\
\hline
\end{tabular}

The WHO core indicators were analyzed using chi square goodness of fit test and the p value was found to be 0 which indicates that there is a significant difference between expected values and observed values.

\section{Potentially Inappropriate Medication:}

Table 5: PIM found in the prescription

\begin{tabular}{|c|c|c|c|}
\hline \multicolumn{4}{|c|}{ PATIENTS } \\
\hline \multicolumn{4}{|c|}{ Potentially inappropriate medication use in geriatrics to avoid: } \\
\hline Digoxin & 06 & $\begin{array}{l}\text { Decreased renal clearance of digoxin may } \\
\text { lead to increases risk of toxic effects }\end{array}$ & $\begin{array}{l}\text { Avoid doses } \\
>0.125 \mathrm{mg} / \text { day }\end{array}$ \\
\hline Chlorpheniramine & 15 & $\begin{array}{l}\text { Highly anti cholinergic; clearance reduced } \\
\text { with advanced age }\end{array}$ & Avoid \\
\hline Nifedipine & 01 & $\begin{array}{l}\text { Potential for hypotension; risk of } \\
\text { precipitating myocardial ischemia }\end{array}$ & Avoid \\
\hline Clonidine & 01 & $\begin{array}{l}\text { High risk of adverse CNS effects; may cause } \\
\text { bradycardia and orthostatic hypotension }\end{array}$ & $\begin{array}{l}\text { Avoid as first line anti- } \\
\text { hypertensive }\end{array}$ \\
\hline $\begin{array}{c}\text { Alprazolam/ } \\
\text { Lorazepam }\end{array}$ & 01 & $\begin{array}{l}\text { Older adults have increased sensitivity to } \\
\text { benzodiazepines and decreased metabolism } \\
\text { of long acting agents }\end{array}$ & Avoid \\
\hline Diclofenac & 01 & $\begin{array}{c}\text { Increased risk of GI bleed or PUD in high risk } \\
\text { groups such as aged }>75 \text {. }\end{array}$ & Avoid chronic use \\
\hline
\end{tabular}

\begin{tabular}{|c|c|c|c|}
\hline \multicolumn{4}{|c|}{$\begin{array}{l}\text { Non infective medications th } \\
\text { function in older adults: }\end{array}$} \\
\hline \multicolumn{4}{|c|}{ Cardiovascular/ hemostasis } \\
\hline Enoxaparin & 01 & $\begin{array}{l}\text { Increased risk of bleeding when creatinine } \\
\text { clearance is }<30 \mathrm{ml} / \mathrm{min}\end{array}$ & Reduced dose \\
\hline Spironolactone & 03 & Increase potassium Levels & If creatinine clearance is $<30 \mathrm{ml} / \mathrm{min}$ \\
\hline \multicolumn{4}{|c|}{ Gastro intestinal } \\
\hline Ranitidine & 05 & $\begin{array}{l}\text { Causes mental status changes when } \\
\text { creatinine clearance is }<50 \mathrm{ml} / \mathrm{min}\end{array}$ & $\begin{array}{l}\text { If use for GE reduce dose }(150 \\
\text { mg/day) }\end{array}$ \\
\hline
\end{tabular}

\section{No. of PIM prescribed during hospital stay}

\begin{tabular}{|l|l|}
\hline None & 66 \\
\hline $\mathbf{0 1}$ & 32 \\
\hline $\mathbf{0 2}$ & 02 \\
\hline
\end{tabular}




\section{Drug-Drug Interactions:}

Table 6: Drug-Drug interactions in prescribed drugs

\begin{tabular}{|c|c|c|}
\hline DRUGS & INTERACTIONS & NO.OF PATIENTS \\
\hline PIPERACILLIN+HEPARIN & Piperacillin increases effect of heparin by anti-coagulation. & 01 \\
\hline CEFTRIAXONE+HEPARIN & $\begin{array}{l}\text { Ceftriaxone increases the effect of heparin by anti- } \\
\text { coagulation. }\end{array}$ & 02 \\
\hline DIGOXIN+METOPROLOL & $\begin{array}{l}\text { Digoxin increases toxicity of metoprolol by unspecified } \\
\text { interaction mechanism. }\end{array}$ & 03 \\
\hline DIGOXIN+PANTOPRAZOLE & $\begin{array}{l}\text { Pantoprazole increases effect of digoxin by increasing gastric } \\
\text { pH. }\end{array}$ & 02 \\
\hline CEFTRIAXONE+FUROSEMIDE & $\begin{array}{l}\text { Ceftriaxone increases toxicity of furosemide by } \\
\text { pharmacodynamics synergism. }\end{array}$ & 07 \\
\hline
\end{tabular}

\section{Polypharmacy:}

Table 7: No. of drugs per prescription

\begin{tabular}{|c|c|}
\hline No. of drugs per prescription & No. of patients \\
\hline$<5$ & 02 \\
\hline $5-10$ & 56 \\
\hline$>10$ & 42 \\
\hline
\end{tabular}

Result: Polypharmacy was found in all the patients.

\section{Distribution of Geriatrics Based on Addictions:}

Table 8: Social history of geriatrics

\begin{tabular}{|c|c|}
\hline \multicolumn{1}{|c|}{ Addiction } & No. of patients \\
\hline Alcoholic & 07 \\
\hline Ex-alcoholic & 04 \\
\hline Smoker & 08 \\
\hline Ex-smoker & 06 \\
\hline Both & 16 \\
\hline Others (tobacco etc) & 02 \\
\hline
\end{tabular}

Results: Incidence of geriatric's addiction is mainly found with both Alcohol and smoking.

(Most of the patients have no history of addiction (57\%) then about 16\% of patients are both Alcoholic and smoker.)

\section{DISCUSSION}

This work was done in Department of General Medicine, Osmania Hospital, over a period of six months. The principle aim of the study was to assess the prescription appropriateness and potentially inappropriate medications (PIM) in geriatrics as per Beer's Criteria, 2015.

In this study, out of 100 patients 70 patients were male and 30 patients were female. The predominance of male patients in this study is similar to other studies conducted in India. ${ }^{13,14,15}$ Majority of the patients belonged to the age group 60-65 years(41\%),followed by age group 66-70 years(29\%),followed by patients above 70 years of age, similar to finding of another study ${ }^{16}$.Most of the patients were non locals and had low socio-economic status.
The morbidity pattern in our study was commonly found to be cardiovascular conditions (36\%) like hypertension, coronary artery disease and congestive cardiac failure. The second most common system affected was CNS conditions $(32 \%)$ such as CVA. Third most common condition was renal disorders $(24 \%)$. Whereas in another study conducted in India, morbidity pattern was cardiovascular diseases (29.33\%), musculoskeletal conditions (27.67\%) and endocrine disorders $(13.34 \%)^{14}$. In our study, only 21 patients had infectious diseases and remaining were noncommunicable diseases. This can be considered as an indicator to show an increasing trend of non-communicable diseases in India.

Most commonly prescribed drugs were cardiovascular drugs(30.4\%),antibiotics(18.2\%),vitamins and mineral supplements(15.4\%) and anti-ulcer drugs(15.9\%),whereas 
Gopinath S et al showed in their study that Antibiotics were prescribed in $62.35 \%$, antiulcer drugs (61\%), anti-anxiety drugs (48\%), Etophylline and theophylline combination $(65 \%)$ was widely used in geriatrics population 17 .

Among the drugs, $\mathrm{B}$ complex vitamin was the most commonly prescribed drug. According to category wise distribution of drugs vitamins, minerals, and dietary supplements were the third most commonly prescribed drugs. Hence, this suggests elderly also suffer from nutritional deficiencies and in our study most patients complained of generalized body pains. There was increase in the use of drugs that decrease gastric acidity such as ranitidine and pantoprazole. This suggests more number of drugs per prescription led to increased prescription of these gastrointestinal drugs to avoid gastric irritation.

According to AGS Updated Beers Criteria 2015 for PIM use in elderly, our study shows almost $34 \%$ of elderly patient had encountered with at least one PIM. Although it is higher than similar study conducted in India 13 , but it is similar to other studies conducted in the USA (27.5\%) and Iran (27.6\%) 34,35 .

PIMs prescribed from the group of drugs to be avoided included Antihistamines which were the most common PIMs prescribed, among which chlorpheniramine maleate was the most commonly prescribed PIM (15 patients) in our study. First generation of antihistamines are included in Beers criteria so other alternative drugs such as second and third generation antihistamines can be used in elderly patients. Beers criteria suggest that non COX selective NSAIDS must be avoided in high risk groups because these drugs increase gastrointestinal bleeding. Digoxin was prescribed to 4 patients in our study in more than the recommended dosage according to Beers criteria. These drugs must be used in dosage of $<0.125 \mathrm{mg}$ /day and less than $25 \mathrm{mg}$ /day in elderly patients. Antipsychotics, tricyclic antidepressants and barbiturates must be avoided in elderly.

Clonidine was prescribed to a elderly patient in our study, it increases adverse CNS effects and hence its use as first line anti-hypertensive agent should be avoided.

Nifedipine was prescribed to a patient in our study, it has a potential for hypotension, risk of precipitating MI and hence should be avoided.

A patient in our study was prescribed Alprazolam, lorazepam. Older adults have increased sensitivity and decreased metabolism of long acting benzodiazepines, hence should be avoided.

Non infective medications that should be avoided or have their dosages reduced with varying level of kidney function in older adults include Ranitidine which was prescribed to five patients in our study. It causes mental status changes when creatinine clearance is $<50 \mathrm{ml} / \mathrm{min}$. Hence dose should be reduced.

Enoxaparin was prescribed to a patient; it increases risk of bleeding when creatinine clearance is $<30 \mathrm{ml} / \mathrm{min}$ and hence the dose should be reduced.

Analysis of prescriptions using WHO drug use indicators showed that the average number of drugs per prescription was 10.85 which is less than a similar study on geriatric population conducted in India, where the average was $5.6^{20}$. Prescription of five or more medications (polypharmacy) was observed in all patients in our study. In contrast, polypharmacy was observed only in $16.5 \%$ patients in a study conducted in Pondicherry 14.

The percentage of drugs prescribed by generic name was $11 \%$, which is very low compared to standard derived or ideal (100\%) 19. Similar studies conducted at Karnataka 18 showed it to be $70 \%$ whereas in a study on geriatric population conducted in Pondicherry ${ }^{14}$ found it to be $21.31 \%$, which is higher than ours.

The percentage of encounters in which an injection was prescribed was $57 \%$, which is much higher than the standard (13.4-24.1\%) derived to be ideal ${ }^{19}$. Whereas, in a similar study conducted in India ${ }^{18}$, it was $26.33 \%$, and is within acceptable limits.

The percentage of encounters in which antibiotics were prescribed was $13 \%$, which is below the standard $(20.0$ $26.8 \%$ ) derived to be ideal ${ }^{18}$. In a similar study conducted in India 14 , it was found to be $23.5 \%$, which is acceptable and higher than our findings.

The percentage of drugs prescribed from the Indian national essential drug list of India was $84 \%$, which is close to the standard (100\%) derived as ideal 19. In similar studies conducted in India, it was less than ours $(76.82 \%)^{14}$.

Drug-interactions found were among piperacillin-heparin, ceftriaxone-heparin, digoxin-metoprolol, digoxinpantoprazole, fluoxetine-metoprolol.

The other drug related problems encountered in geriatrics in the present study were prescription of antibiotics without indication, prescription of Aspirin which should be avoided in patients $>80$ years as risk out-weighs benefits and Metformin which should not be used in patients $>80$ years unless normal renal function established and syrup cremaffin which is a laxative agent was prescribed in patient suffering from diarrhoea.

\section{CONCLUSION}

The study showed high prevalence of Potentially Inappropriate Medications (34\%) as per Beer's criteria, 2015.Polypharmacy was seen in all the patients included in the study. The WHO core indicators were assessed using ChiSquare Goodness-of-Fit-Test and the p-value was found to be significant which indicates there is a statistical difference between observed values and expected values (standard values).

Reducing the rate of medication errors in geriatric patients is a challenging task due to comorbidities, multiple prescribers, polypharmacy, non-adherence, lack of sufficient efficacy and safety evidence of medications.

There is an enormous need of future research work, strategies and regulatory measures which should focus on specific evidence in older patients. Regular CMEs on use of Rational Drug Prescription and use of Beer's criteria among clinicians should be promoted while prescribing elderly. Availability of clinical pharmacology and clinical pharmacy practices for better healthcare outcomes needs to be increased.

\section{ACKNOWLEDGEMENT}

We would like to express our great appreciation to Dr. Vemuri Hanumanth Shastry, Dr. Javed Akhtar Ansari, Dr. Areefulla Hussainy, Syed Rana Nikhat and Dr. Reshma Begum for their valuable and constructive suggestions during the planning and development of this research work. We express our sincere regards and respect to MESCO College of Pharmacy and Osmania General Hospital, Telangana for their support and kind cooperation. 


\section{REFERENCES}

1. Patridge L, Mangel M. Messages from mortality: the evolution of death rates in the old. Trends Ecol Evol. 1999; 14(1):438-42.

2. Geriatric knowledge today elderly population. Available at http:/www.gktoday.in/indias-elderlypopulation-somefundamentals /

3. British Geriatric Society-definition-geriatrics. Available at http:/www.bgs.org.uk/index.php/policydigest/228about/administration/981geriatricsdefined.

4. Madgaonkar CS. Family medicine. A clinical and applied orientation 2 nd Ed Jaypee medical publishers (p) lt.

5. Public relations bureau-reports-elderly population 2012. Available at

http:/www.prb.org/publications/reports/2012/indiaolderpopulation.aspx. d; 2015:247.

6. Jiron M, Pate V, Hanson LC, Lund JL, Jonsson Funk M, Strümer T. Trends in prevalence and determinants of potentially inappropriate prescribing in the United States: 2007 to 2012. J Am Geriatric Soc. 2016; 64(4):788-97.

7. Suehs BT, et al. Effect of potentially inappropriate use of antimuscarinic medications on healthcare use and cost in individuals with overactive bladder. J Am Geriatr Soc. 2016; 64(4):779-87

8. Page RL, II SA, Bryant LL, Ruscin JM. "Inappropriate prescribing in the hospitalized elderly patient: defining the problem, evaluation tools, and possible solutions". 2010; 75-87,

9.Sisay M, Mengistu G, Molla B, Amare F, Gabriel T. Evaluation of rational drug use based on World Health Organization core drug use indicators in selected public hospitals of eastern Ethiopia: a cross sectional study. BMC Health Serv Res. 2017; 17(1):161. Published 2017 Feb 23. Doi: 10.1186/s12913-017-2097-3

10. Panel, A.G.S.B.C.U.E, et al. American Geriatrics Society 2015 updated beers criteria for potentially inappropriate medication use in older adults. J Am Geriatr Soc. 2015; 63(11):2227-46.

11.Lu WH, Wen YW, Chen LK, Hsiao FY. Effect of polypharmacy, potentially inappropriate medications and anticholinergic burden on clinical outcomes: a retrospective cohort study. CMAJ. 2015; 187(4):E130-7.

12.Fick DM, Mion LC, Beers MH, L. Waller J. Health outcomes associated with potentially inappropriate medication use in older adults. Res Nurs Health. 2008; 31(1):42-51.

13.Zaveri HG, Mansuri SM, Patel VJ. Use of potentially inappropriate medicines in elderly: A prospective study in medicine outpatient department of a tertiary care teaching hospital. Indian J Pharmacol 2010; 42(2):95-8

14.Kanagasanthosh K, Topno I, Aravindkumar B. Prevalence of potentially inappropriate medication use and drug utilization pattern in elderly patients: A prospective study from a tertiary care hospital. Int J Res Med Sci 2015; 3(8):2062-72.

15.Shah RB, Gajjar BM, Desai SV. Drug utilization pattern among geriatric patients assessed with the anatomical therapeutic chemical classification defined daily dose system in a rural tertiary care teaching hospital. Int J Nutr Pharmacol Neurol Dis 2012; 2(3):258-65.

16.Prasad SN, Revankar S,Vedavathi H, Chidanand KN, Murray JL,Manjunath H. A study on prescription analysis and utilization of antibiotics in geriatric in-patients admitted in Shimoga institute of medical sciences tertiary care hospital, Shimoga, Karnataka, India.Int J Basic Clin Pharmacol 2016; 5:904-9.

17.Gopinath S, Rajalingam B, SriramS, Subash V. An individual based study of the geriatric population: a polypharmacy.International Journal of Pharmacy and Pharmaceutical Sciences. 2011; 3(4):63-6
18.Nayaka SR, Rajeshwari B, Venkatadri TV. Drug utilization pattern in geriatric inpatients of medicine department in a Tertiary Care Teaching Hospital. Int J Basic Clin Pharmacol 2015; 3(4):568-73.

19.Isah AO, Ross-Degnan D, Quick J, Laing R, Mabadeje AF. The development of standard values for the WHO drug use prescribing indicators. ICUM/EDM/WHO. Available from: http://www.archives.who.int/prduc2004/rducd/ICIUM_Poster s/1a2_txt.htm.

20. Prasanjit K Debnath* et al.A Study of drug utilization pattern of geriatric patients in the department of geriatric medicine in geriatric in a tertiary care hospital, Guwahati, Assam, India. Asian J Pharm Clin Res, 2010; 10(2):122-126

21.Supriya KH, Shashikumar NS, Prakash GM, Sareetha AV. A prospective observational study of prescription appropriateness of elderly hypertensive patients using Beers criteria in a tertiary care teaching hospital. Int J Basic ClinPharmacol 2017; 6:2545-50

22.Austin RP. Poly-pharmacy a risk factor in the treatment of type 2 diabetes. Diabetes Spectrum. 2006; 19(1):13-6.

23.C. S. van der Hooft et al Inappropriate drug prescribing in older adults: the updated 2002 Beers criteria - a population-based cohort study.Br J ClinPharmacol.

24. D. Fialová\& G. Onder Medication errors in elderly people:contributing factors and future perspectives $\mathrm{Br} J$ ClinPharmacol DOI:10.1111/j.1365-2125.2009.03419.x

25.Prakash Goudanavar et al.: Asian Journal of Biomedical and Pharmaceutical Sciences, 2016; 6(56):23-27.

26.AnithaNandagopal et al. Assessment of Rational Drug Prescribing Pattern in Geriatric Patients in Hyderabad Metropolitan Indian Journal of Pharmacy Practice, 2017; 10(3).

27.Neha Sharma et al.Screening of prescriptions in geriatric population in a tertiary care teaching hospital in north India The Journal of Phytopharmacology 2013; 2(5):38-45.

28.Bhaveshaikh $\mathrm{N}$ et al. Drug prescribing patterns in elderly patients in a tertiary level hospital Int J Basic ClinPharmacol. 2017 Apr; 6(4):759-764

29.Binaya Shrestha et al Assessment of Drug Use Pattern Using WHO Prescribing Indicators JNHRC 2018; Vol. 16 No. 3 Issue 40

30.Eman Elayeh et al. Assessment of appropriate medication use by 2015 Beers criteria among elderly critically ill patients in Jordan Clin. Pract. 2018; 15(4):765-774

31.. Sultan H, Sayegh K, Mohammad A, et al. Prescribing pattern of drugs in the geriatric patients in jazan province, KSA. Pharm

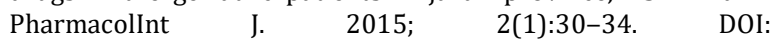
10.15406/ppij.2015.02.00013

32 Edward K. Osei et al. Prevalence of Beers Criteria Medications Among Elderly Patients in a Military Hospital.Gerontology\& Geriatric Medicine Volume 2: 1-6

33. Hsu WH, Hsiao PJ, Lin PC, Chen SC, Lee MY, Shin SJ. Effect of metformin on kidney function in patients with type 2 diabetes mellitus and moderate chronic kidney disease. Oncotarget. 2017; 9(4):5416-5423. Published 2017 Dec 17. doi:10.18632/oncotarget.23387

34.Gavilán Moral E, Morales Suárez-Varela MT, Hoyos Esteban JA, Pérez Suanes AM. Inappropriate multiple medication and prescribing of drugs immobile elderly patients living in the community. Aten Primaria. 2006; 38(9):476-480

35.Steinman MA, Landefeld CS, Rosenthal GE, Berthenthal D, Sen S, Kaboli PJ. Polypharmacy and prescribing quality in older people. J Am Geriatr Soc. 2006; 54(10):1516-1523 